\title{
Understanding Meta-Emotions: Prospects for a Perceptualist Account
}

DOI:

10.1017/can.2019.47

Document Version

Accepted author manuscript

Link to publication record in Manchester Research Explorer

\section{Citation for published version (APA):}

Mitchell, J. (2019). Understanding Meta-Emotions: Prospects for a Perceptualist Account. Canadian Journal of Philosophy. https://doi.org/10.1017/can.2019.47

\section{Published in:}

Canadian Journal of Philosophy

\section{Citing this paper}

Please note that where the full-text provided on Manchester Research Explorer is the Author Accepted Manuscript or Proof version this may differ from the final Published version. If citing, it is advised that you check and use the publisher's definitive version.

\section{General rights}

Copyright and moral rights for the publications made accessible in the Research Explorer are retained by the authors and/or other copyright owners and it is a condition of accessing publications that users recognise and abide by the legal requirements associated with these rights.

\section{Takedown policy}

If you believe that this document breaches copyright please refer to the University of Manchester's Takedown Procedures [http://man.ac.uk/04Y6Bo] or contact uml.scholarlycommunications@manchester.ac.uk providing relevant details, so we can investigate your claim.

\section{OPEN ACCESS}




\title{
Understanding Meta-Emotions: Prospects for a Perceptualist Account
}

Jonathan Mitchell (jonathan.mitchell@manchester.ac.uk); University of Manchester - forthcoming in Canadian Journal of Philosophy

\begin{abstract}
This article clarifies the nature of meta-emotions, and surveys the prospects of applying a version of the perceptualist model of emotions to them. It first considers central aspects of their intentionality and phenomenal character. It then applies the perceptualist model to meta-emotions, addressing issues of evaluative content and the normative dimension of meta-emotional experience. Finally, in considering challenges and objections, it assesses the perceptualist model, concluding that its application to metaemotions is an attractive extension of the theory, insofar as it captures some distinctive features of meta-emotions - specifically their normative dimension - while locating them within the domain of occurrent affective experiences.
\end{abstract}

KEYWORDS: Meta-emotion; Emotion; Perceptualism; Experience; Intentionality

\section{Introduction}

Despite an upsurge of research in the philosophy of emotion, the topic of meta-emotions remains comparatively unexplored. However, consideration of one's emotional life and that of others' attests to the prevalence of emotions about emotions; jealousy about a competitor's joy, or embarrassment about my own anger, are common. ${ }^{1}$ This article offers two things to clarify their nature. First, it explains the intentionality and phenomenal character of metaemotions, arguing that meta-emotions are intentional affective experiences necessarily directed toward other emotions. Second, it considers how a prominent version of the perceptual model of emotions can be applied to meta-emotions. ${ }^{2}$ My aim is to facilitate a better understanding of the central features of meta-emotions and assess the prospects of a perceptualist account.

The discussion proceeds as follows. Section 1 explains aspects of the intentionality and phenomenology of meta-emotions. Section 2 outlines what I call basic case meta-emotions. Sections 1 and 2 also argue that feeling and judgement theories encounter problems when applied to meta-emotions. Section 3 then offers a perceptualist theory of meta-emotions,

\footnotetext{
${ }^{1}$ More has been said about meta-emotions in the psychological than philosophical literature; see Bartsch et al. 2010: 167-90; Koven 2011: 1255-61; Mitmansgruber et al. 2009: 448-53; Norman and Furnes 2016: 187-93. On the philosophical side see Jäger and Bartsch 2006: 179-204; Jäger and Bänninger-Huber 2015: 787-811; Mendonça 2013: 390-396; Howard 2015: 1-23.

${ }^{2}$ For an overview of the perceptual model, see Döring and Lutz 2015: 259-70.
} 
where the central claim is that meta-emotions are affective perceptual experiences of the evaluative properties of their target emotions. I explore entailments of this view regarding its view of meta-emotional content and highlight its ability to explain the role of meta-emotional experience in disclosing what I call the 'normative status' of the emotions that they target. Finally, section 4 considers challenges for the view.

Before proceeding, I address a concern. It might be asked why philosophers of emotion ought to care about meta-emotions as a supposedly distinct class of emotions. What reasons are there for thinking that analyses of meta-emotions will encounter distinct problems, or provide helpful resources, not already found in standard analyses of emotion? As will be seen, many of the distinctions and features typical of emotions apply to meta-emotions. Recognizing this, however, is important to placing meta-emotions within the domain of occurrent affective experiences. Yet, there are distinctive features of meta-emotions that need accounting for, and problems that arise in analyzing them, therefore motivating the claim that they form a distinct category of emotion. These concern some of the following: perceptions of other emotions; experience of one's emotional responses; the relation between metaemotions and emotions appropriateness; the role of meta-emotions in guiding reflection on emotions. The perceptualist model does not definitively solve all the problems that arise in relation to these issues; nonetheless, it provides clarifications which reflect what is distinctive about meta-emotions. Further to this, the resources drawn on in applying the perceptual model to meta-emotions go beyond those standardly appealed to in discussions of that model. As such, this paper extends the perceptualist model to meta-emotions, rather than merely taking it to already apply to them.

Finally, let me say something about what I will call 'Howards Challenge'. Scott Alexander Howard, claims that a widely-accepted claim about emotional intentionality is false regarding a specific kind of meta-emotion. Emotions are cognitively mediated states in that they are not self-standing intentional relations to their objects, but (partly) get their intentional content from non-emotional psychological states (e.g. beliefs, perceptions, imaginations) - their socalled 'cognitive bases' (Howard calls this the 'tripartite' model of emotional intentionality). ${ }^{3}$ However, in the case of reflexive meta-emotional experiences this 'basing thesis' is arguably false: meta-emotions whose objects are our own occurrent emotional experiences do not require any separate mediating representational state. Given that the object is my own occurrent experience, I can be directly aware of it precisely insofar as I experience it. 'Howard's Challenge' is that any theory of emotion applied to meta-emotions should respect this data point, such that reflexive meta-emotions remain self-standing intentional relations to the emotions which they are about. The discussion that follows makes distinctions relevant to

\footnotetext{
${ }^{3}$ See Howard 2015: 1-4; on the basing thesis, see Teroni 2007: 404.
} 
this challenge, and the challenge is explicitly met in the context of the perceptual model in section 4.1.

\section{Intentionality and Phenomenology}

Meta-emotions are emotions about other emotions; they necessarily have other emotions as their objects or targets, as what they are directed towards. Consider the following examples. One evening I am in conversation with a friend, and the topic moves onto a conflict overseas. I see my friend is incensed about this conflict, as she becomes angry when describing it. I then experience admiration for her anger about the conflict. Alternatively, one evening I am at a restaurant and become angry with the waiter about the long delay in the arrival of the entrée. After the waiter departs, I am overcome with embarrassment at my anger.

The picture described by these examples is familiar; we often experience emotions that seem to be about other emotions. There are interesting differences between the cases, notably that in the first the emotion is about the emotion of another person (non-reflexive), and in the second, my own (reflexive). Discussion is often restricted to reflexive cases in the philosophical literature on meta-emotions. ${ }^{4}$ However, while there are important differences, and problems, associated with non-reflexive and reflexive meta-emotions (see section 4.1), this should not undermine referring to both as meta-emotions, insofar as both are (minimally) emotions about emotions. Indeed, in the psychological literature there is agreement that metaemotions at least involve emotions about emotions. ${ }^{5}$ This terminological heuristic is analogous to standard emotion theory, which does not allocate reflexive and non-reflexive emotions into fundamentally different kinds - both are instances of emotion. So, a restriction to reflexive cases is unnecessary. Furthermore, we run the risk of skewing our analysis if we start by focusing exclusively on reflexive cases, which likely have distinctive features. More positively, an account with considers both reflexive and non-reflexive cases, and elucidates their shared features, can provide a unified account of a central class within the affective domain - namely, meta-emotions per se. And while nothing in principle blocks further metaiterations - an emotion about an emotion about an emotion (etc.) - for simplicity's sake, I focus on emotions about other emotions. ${ }^{6}$

\footnotetext{
${ }^{4}$ See Jäger and Bartsch 2006: 179-204; Mendonça 2013: 391.

${ }^{5}$ See Norman and Furnes 2016: 187-93.

${ }^{6}$ Cf. Jäger and Bänninger-Huber 2015: 791. The language of first-order and second-order is not helpful in discussions of meta-emotions. While it can make sense to adopt this heuristic for reflexive metaemotions (embarrassment [second order] at my anger [first order]), this terminology is not applicable in cases for non-reflexive meta-emotions.
} 
However, a critic might question whether the considerations motivating the idea that metaemotions are necessarily emotions about emotions could not be applied to motivate postulating a distinctive class of emotion for any restriction on types of objects. For example, let 'event-emotion' refer to any emotion directed at an event - should we, therefore, have a distinct account of event emotions? In response, we can say the following: the fact that 'eventemotions' are necessarily about events is best explained by simply looking at a stipulation in language, as a purely definitional issue (and events, along with physical particulars, persons and states of affairs, are usually classified by emotion theorists as one of the types of 'particular objects' which emotions target). Contrastingly the way meta-emotions are about emotions - necessarily taking emotions as their objects - is not merely a definitional issue, but may point toward understanding how meta-emotions constitute a distinctive category of emotion, raising their own issues and motivating a separate treatment. That is as pointing toward a philosophically interesting category of emotion.

So, given that meta-emotions can be framed minimally as emotions about other emotions, we can distinguish them from superficially similar affective states, such as emotional responses directed towards (a) non-affective conscious states, and (b) affective dispositions. Taking (a) I can be irritated by Bill telling me he believes that Trump is an excellent president, but there is no target emotion here, and so no meta-emotion. Regarding (b), I may experience my partner's tendency to be jealous as offensive, yet insofar as my anger is directed at that disposition, rather than a realization of it in an emotional episode, it would not be an emotion about an emotion.

Building on the above, meta-emotions have intentional content: they present the relevant target emotion to their subject, where 'target emotion' is shorthand for the emotion a metaemotion is about as constituting a significant part of the intentional content. Importantly though, meta-emotions also present their target emotions under certain aspects - what in theory of intentionality is called 'aspectual shape'. For example, in a visual perceptual experience, my experience presents the table as red and rectangular, as having certain determinations and not others. And it is by specifying how the experience presents its object under a certain aspect that we specify the content. ${ }^{7}$ In the case of meta-emotions, this aspectual shape will be the evaluative property connected to the meta-emotional response. Let me explain. Take the case of embarrassment about anger: it presents its object, the emotion of anger, under the aspect of the embarrassing. Alternatively, consider shame about lust: it presents its object, the emotion of lust, under the aspect of the shameful. The precise way in which these evaluative properties are appraised of target emotions (e.g. through judgement or perception) will concern us later. However, clarifying further, it is essential to meta-emotions

\footnotetext{
${ }^{7}$ See Crane 1998: 86-7 and Searle 1994: 131.
} 
that they present their target emotions under evaluative aspects; embarrassment about anger would not be embarrassment unless it presented that anger under the aspect of the embarrassing. There is, therefore, a conceptual connection here between the meta-emotiontype and how it presents its object. ${ }^{8}$

Further to the above, we can emphasize that meta-emotions are - like paradigmatic emotional experiences - first-order intentional experiences. That is to say, they are not higherorder thoughts about meta-emotional responses. While one's meta-emotional responses may on reflection become intentional objects, first and foremost they are directed at their target emotions. For example, if I were to report a meta-emotion by saying that it involved 'feelings of admiration toward anger', it is only the 'toward anger' which is intentional. The 'of' in 'feelings of admiration toward anger' is one of specification - telling us about the kind of meta-emotion we are undergoing - and so should not be thought of as a higher-order awareness of admiration toward anger. ${ }^{9}$ For the moment these points suffice for thinking about the intentionality of meta-emotions. ${ }^{10}$

Building on the above, I focus on occurrent meta-emotions, as meta-emotional experiences enjoyed by individuals at particular times, rather than meta-emotional dispositions (e.g. a disposition to be jealous when my competitors are happy), unconscious meta-emotions, or long-lasting meta-emotions. ${ }^{11}$ This focus is not unmotivated since as seen in the examples meta-emotions often manifest as occurrent experiences.

Given this focus on meta-emotions as occurrent affective experiences, they will have a phenomenal character - there is something it feels like to experience them (what-it-islikeness). For example, there is something-it-is-like to feel occurrent admiration for your anger. In the context of phenomenality, we can ask how feeling theories would characterize meta-emotions. According to Jamesian feeling theories emotions are 'perceptions' (interoceptive awareness) of bodily changes; their causes, or 'exciting facts', are not part of the emotion itself (although in classical feeling theories, as found in Descartes and Spinoza,

\footnotetext{
${ }^{8}$ There may be complex situations in which various emotions and meta-emotional responses are in play. For the sake of simplicity, I bracket these in favour of the simpler ones where there is just the target emotion and the meta-emotional response to it. However, in reflexive meta-emotions it is plausible that the emotion is presented as mine (embarrassment at my anger), so this would arguably be another aspect under which the target emotion was presented (as part of the content). I thank an anonymous referee for suggesting clarifying these points.

${ }^{9}$ See Marcel and Lambie 2002: 219-59 for a similar claim about emotions.

${ }^{10}$ The examples used borrow terms from standard emotions. While such cases are instructive, there is no reason for restricting meta-emotions to those with familiar emotion terms on either the left or righthand side of the intentional specification.

${ }^{11}$ See Jäger and Bänninger-Huber 2015: 795 for discussion.
} 
bodily perturbations are accompanied by an idea of their cause). ${ }^{12}$ However, on such a view, meta-emotions would not refer to a distinctive type of intentional state in the affective domain; they would not be distinctive in virtue of having a specific type of intentional object. Rather 'target emotions' would be one possible 'exciting fact' which can cause a conscious emotion, as constituted by awareness of bodily changes. So, on feeling theories, there is no distinctive type of meta-emotional experience per se, any more than there is, for example, a distinctive type of emotional experience associated with any class of 'exciting facts' which contingently cause an emotional episode.

Even if we resist feeling theories as applied to meta-emotions, we might ask whether their phenomenal character should be somatically characterised. However, consider that there are arguably 'cool' or 'calm' emotional experiences, such as admiration, pity, reverence, regret, or hope, that can occur without any attendant bodily phenomenology, such that somatic states are not necessary for their occurrence. ${ }^{13}$ And this point carries over for meta-emotions. While the 'hot' meta-emotion of anger about a partner's jealousy will involve somatic accompaniments typical of anger (e.g. muscle tensing), regret at another's happiness, or admiration for another's anger, seems possible without accompanying somatic states - these would be 'cold' or 'calm' meta-emotions.

Nonetheless, whatever we say about the presence of bodily feelings, meta-emotions will have some affective phenomenology; they will involve feelings of some sort, which need clarifying in an analysis. This constraint is motivated, in part, by needing to distinguish between meta-emotional experiences and other occurrent intentional states which take emotions as their intentional objects. For example, I could believe that my partner is angry about $\mathrm{X}$, or perceive that they are angry about $\mathrm{X}$, without experiencing any emotional response. Part of the difference in the meta-emotional case will be the presence of affective phenomenology. I return to this issue when discussing the perceptual model.

Building on the above, meta-emotional phenomenology will be valenced in virtue of involving a positive or negative component of some sort - as we shall see in section 3 the perceptual model has a distinctive take on this. For now, it suffices to note that meta-emotions will likely have a valenced phenomenal character. ${ }^{14}$ However, the objective valence mark of the meta-emotion - as something different from any valenced feelings involved in the experience - need not match the valence of its target emotion. There are four possible valence mark pairings: negative-negative (e.g. embarrassment towards anger); positive-positive (e.g.

\footnotetext{
12 See James 1884: 188-205.

${ }^{13}$ See Lambie 2009: 272-280; Poellner 2016: 13; Stocker 2010: 401-23.

${ }^{14}$ See Jäger and Bänninger-Huber 2015: 789. Not all emotion theorists accept that emotions have a valenced phenomenology (see Zagzebski 2003: 104-24).
} 
joy towards happiness); negative-positive (e.g. jealousy towards happiness); and positivenegative (e.g. happiness towards sadness).

Finally, meta-emotions are experienced as motivated by their target emotions. For example, my pity for your sadness about $\mathrm{X}$ is experienced as motivated by that sadness - as a kind of intentional causality. ${ }^{15}$ Two central ideas of intentional causality applied to metaemotions are that I am in a position to know straight off (without additional investigation), and so on the basis of the meta-emotion alone, (a) the target emotion that seemingly motivated my meta-emotional response and (b) the relevant counterfactual; if you did not display a sad countenance, I would not have felt pity for your sadness. ${ }^{16}$ This kind of experienced motivation should not be conflated with knowledge of what caused the response. As Nico Fridja claims when discussing emotional experience 'known causation...is different from experienced motivation'. ${ }^{17}$

So, what is the cause and what is experienced as motivating the meta-emotion (the intentional object), can come apart, although in such cases this typically will not be salient for the subject while undergoing the experience. For example, I might experience embarrassment about my partner's anger towards the late waiter as motivated by that anger, as presented under the aspect of the embarrassing. However, the actual cause of my embarrassment is that the waiter looks strikingly similar to a previous partner of mine, a feature of the situation which while opaque to me at the time, is brought to light later when I reflect on why I was so embarrassed by my partner's anger. The point is that what seems to motivate meta-emotional responses and what causes them need not always be the same. And while in certain cases I may, through reflection, realise the relevant disconnect, there is no requirement on doing so (I may confabulate and self-deceive). What matters is that target emotion seems to motivate the meta-emotional response; my partner's anger toward the waiter seems to be what motivates my embarrassment at their anger, and it is its seeming so that matters given the focus on occurrent experiential states.

We now have a preliminary characterization of the intentionality and phenomenology of meta-emotional experience. However, let me emphasize that the claims made so far about meta-emotions - namely that they are intentional, have a valenced phenomenology, are experienced as motivated by their intentional objects, alongside the possibility of 'cold' or 'calm' meta-emotional states in which there need be no accompanying somatic

\footnotetext{
${ }^{15}$ See Searle 1983: 112-140.

${ }^{16}$ The 'display' caveat is necessary since overt behaviour can be misleading (and subjects can be aware of this). I thank an anonymous referee for suggesting this clarification.

${ }^{17}$ See Frijda 1987: 252-3.
} 
phenomenology - are arguably true of emotional experiences. ${ }^{18}$ In this sense, there is no claim that these features are distinctive to meta-emotions. However, emphasizing them is important, since in doing so we place meta-emotions in the domain of occurrent affective experiences. And it is meta-emotions, so understood, that concern me for the rest of this paper.

\section{Basic Cases and the Judgement Theory}

\subsection{Basic vs non-basic cases}

I now motivate a further distinction within the class of meta-emotional experiences between what I will call basic and non-basic cases. I suggest that basic case meta-emotions are those in which the target emotion is directly presented to the subject. A clear example of a basic case meta-emotion in this sense would be one whose target emotion was directly present on the basis of sense-perception, for example, being embarrassed by my partner's anger at the waiter while witnessing it. In such a case my visual experience serves to directly present the relevant target emotion. Alternatively, as a basic case scenario for a reflexive case, consider embarrassment about my anger concerning my partner's lateness - I am experientially acquainted with that occurrent anger, and so am directly presented with it. Further details of how we can be directly presented with target emotions in this way, in both non-reflexive and reflexive cases, and problems this gives rise to, will be considered when examining the perceptual model.

By way of contrast, consider the following non-basic cases. When I entertain the belief that my friend is in awe of the successes of the British Empire I experience repugnance about that awe. Alternatively, when recollecting the lustful feelings I experienced yesterday for an individual other than my partner I am overcome with guilt about that lust. In both cases, I am not directly presented with the target emotion, rather is merely judged to have obtained. As such, we can say that the target emotion is represented indirectly. ${ }^{19}$

Let me note a caveat concerning basic cases meta-emotions. Importantly the claim concerning direct presentation does not have to extend to the particular object of the target emotion itself. For example, I might respond with anger at my friend's directly presented indignation, as I visually witness their incandescent outbursts. Yet, the particular object of my friend's indignation need not be perceptually present to either of us for this be classified as a basic case. For example, my friend might be visibly indignant about a past slight they are now

\footnotetext{
${ }^{18}$ Typically, meta-emotions (like emotions) also have a behavioural component. I leave it open how to characterize this.

${ }^{19}$ Poellner 2016: 1-2 makes this distinction in the context of the perceptual model of emotion. See also Eisenberg 1996: 269-76, on how meta-emotions influence behaviour without mediating thoughts or beliefs.
} 
recounting, making their emotion a non-basic case (where the particular object is indirectly represented on the basis of verbally recollecting a past event), but nonetheless, my anger at their indignation is not - their indignation is directly presented to me. So, the scope of the basic vs non-basic distinction concerns the direct presentation (or not) of the relevant target emotion, not the direct presentation (or not) of the particular object of the target emotion.

It might, however, be questioned how a theory of meta-emotions can coherently hold that both cases, basic and non-basic, exist, even though we have the same name for them, namely meta-emotions. However, on this point, we need to re-emphasize that meta-emotions, both basic and non-basic, are affective experiences directed at target emotions. The precise way in which they are so directed may differ in important respects - we can fruitfully distinguish between direct presentation and indirect representation of the target emotion - yet across cases we are still dealing with meta-emotions.

Here is a further important clarification. The notion of basic cases is not to be simply equated with Ekman's 'basic emotion theory' in emotion psychology, where that involves claims such as that basic emotions are universally shared, where universality is measured on the basis of (i) recognizing cross-cultural facial features (for Ekman), (ii) evolutionary history in helping humans overcome specific challenges (as phylogenetically basic responses), and/or (iii) dedicated neural underpinnings. ${ }^{20}$ Somewhat in contrast, the idea of basic vs non-basic meta-emotions is a distinction between types of cases in terms of whether the relevant target emotion is directly presented or indirectly represented. Note though, if the idea of 'basic emotions' merely stands for those cases which are 'noncognitive' affective experiences, then there may be cross over. However, what is precisely meant by 'noncognitive' affective experiences would need cashing out in detail. For the sake of the discussion here let's just maintain the distinction as outlined between basic and non-basic cases.

\subsection{The judgement theory}

While it may be granted that basic case meta-emotions do not require indirect representations (e.g. thoughts, judgements) of their target emotions for their occurrence, nonetheless there is a view which would argue that all meta-emotions, basic and non-basic cases, are constituted by evaluative judgements about target emotions. ${ }^{21}$ On such a view to be embarrassed about my anger at $\mathrm{X}$ would be, in significant part, to $j u d g e$ that my anger at $\mathrm{X}$ is embarrassing; likewise, to experience pity for your sorrow about $\mathrm{X}$ would be, in significant part, to judge that your sorrow about $\mathrm{X}$ is pitiful. Note, the judgement theory can maintain the distinction between basic and non-basic cases. Take the following example. In a basic case (as defined)

\footnotetext{
${ }^{20}$ See Ekman 1999: 384-92. I thank an anonymous referee for suggesting clarifying this point.

${ }^{21}$ See Nussbaum 2001 and Solomon 1976.
} 
I am embarrassed by your anger which I am currently witnessing, and which is directly presented to me (say through visual experience). Yet, in addition, there is an evaluative appraisal of that anger as embarrassing which takes the form of doxastic representational state, namely a judgement. In this sense, meta-emotions, on the judgement, theory, are doxastic representations of the evaluative properties of the relevant target emotions.

Given the above, a judgement theory of meta-emotions invokes a distinction, often made in emotion theory, between 'particular' and 'formal' objects, where the latter are evaluations applied to the 'particular' objects. ${ }^{22}$ For a meta-emotion, the particular object would necessarily be the target emotion, and the formal object would be the (putative) evaluative properties those target emotions are appraised as possessing through judgement. This view, therefore, provides one way of substantiating the claim (made in section 1), that metaemotions present their target emotion 'under the aspect' of the relevant emotional response. Insofar as embarrassment about Bill's anger represents anger 'under the aspect' of the embarrassing, it involves an evaluative judgement of that anger as embarrassing. As such, the content of the judgement would approximate to 'Bill's anger is embarrassing'. I return to issues of evaluative representation in section 3 , after considering problems with applying judgement theory to meta-emotions below.

One problem is that evaluative judgements about target emotions - that your anger at $\mathrm{X}$ is embarrassing, or that your sorrow about $\mathrm{X}$ is pitiful - can be sincerely made without undergoing the relevant meta-emotion; evaluative judgements about emotions are not sufficient for the occurrence of a meta-emotion. Perhaps the judgement theory could respond that they are at least necessary. What might be further required is adding on a phenomenological component which, along with the evaluative judgement, constitutes a meta-emotion (rather than just a non-emotional evaluative judgement about the target emotion). However, regardless of the success of such a strategy, a stronger line of argument against judgement theories can be made, which draws on emotional recalcitrance. First, I survey this line of criticism in the standard case and then suggest similar considerations apply to meta-emotions.

A significant strand of criticism of judgement theories points to cases of emotional recalcitrance, in which emotional episodes persist even when they contradict the content of judgements held simultaneously. Somewhat like perceptual illusions, the emotion persists even after one has been appraised of the relevant fact or sincerely makes the relevant judgement (e.g. the stick is not bent, the spider is not dangerous). If emotional experiences were necessarily constituted by evaluative judgements, emotional recalcitrance would involve assenting to logically contradictory propositional contents, given judgements are expressed

${ }^{22}$ See Kenny 1963: 132 and Teroni 2007: 395-415. 
in the indicative mood (e.g. 'the spider is dangerous, and it is not the case that the spider is dangerous'). Yet, there is a difference between the strength of the rational norms in play when someone is assenting to conflicting judgements, and when someone's emotions are not in line with their sincerely avowed better evaluative judgement. Typically, if we want to avoid irrationality, we give up one of the conflicting propositions. Yet, it is neither typically possible for the emotionally recalcitrant subject to 'give up' the emotion, nor rationally required for them to retract the sincerely held 'better' judgement. While there is more to be said about this, one plausible explanation of this difference between the strength of the rational norms in play is that emotional experiences do not involve evaluative judgements. ${ }^{23}$

Similar considerations carry over for meta-emotions. Consider a case of meta-emotional recalcitrance. Say I cannot help feeling shame after feelings of love for X, and yet I sincerely judge that I have nothing to be shameful about - I judge that my feelings of love for X are not shameful. Yet, the meta-emotion persists - it is recalcitrant to my sincere (better) metaemotional evaluative judgement. If meta-emotional experiences were necessarily constituted by evaluative judgements about their target emotions, then meta-emotional recalcitrance would involve assenting to logically contradictory propositional contents, and so would involve irrationality. In the case described this would amount to consciously judging that 'feelings of love for $\mathrm{X}$ are shameful', and at the same time that 'it is not the case that feelings of love for $\mathrm{X}$ are shameful'. Yet, analogously to above, there is a difference between the strength of the rational norms governing the kind of conflicts when someone is assenting to directly conflicting evaluative judgements about their meta-emotions, and when someone's meta-emotions are not in line with their sincerely avowed better evaluative judgements about them. Again, one plausible explanation of this difference is that meta-emotional experiences do not involve evaluative judgements.

It might be responded that this argument from emotional recalcitrance only carries over if meta-emotions are emotions about emotions; although the judgement theory would have to give us good reason to abandon this claim. Although, they could suggest that there are further intentional and phenomenological features of meta-emotions that count in favour of their theory. For example, the idea that meta-emotions involve evaluations of their target emotions is important and can be explicated on the judgement theory by appeal to evaluative judgments. However, resisting an evaluative judgment theory need not involve giving up the claim that meta-emotions involve appraisals of their target emotions. It is just that, given the above considerations, there are reasons to question whether the representational state which plays that role will be a judgement. I now present a different account of meta-emotions evaluative

\footnotetext{
${ }^{23}$ For further discussion, see Helm 2001: 190-213; Brady 2007: 273-84; Döring 2014: 124-26.
} 
aspect, which is a phenomenologically more appealing alternative and further clarifies their distinctiveness.

\section{A Perceptualist Account of Meta-Emotions}

\subsection{Outlining the model}

In what follows I provide a perceptualist account of meta-emotions which builds on the analysis given so far. The perceptual model is, however, only one option, although for reasons highlighted feeling and judgement theories encounter problems, and so unless those problems can be overcome such theories should be avoided. ${ }^{24}$ To start, it is helpful to say something about recent perceptual theories, according to which emotions are perceptual experiences of value.

One commentator provides the following summary: 'According to this view emotional experiences in favourable circumstances disclose value properties to the subjects of those experiences, properties that are, in the basic cases, typically instantiated in the subjects' environment...in fear I may have a perceptual experience of an object's or event's fearsomeness, in aesthetic admiration I can become acquainted with an object's determinate beauty... ${ }^{25}$ Given the idea that emotional experience discloses evaluative properties, as qualifying the objects of those experiences, a central claim of the perceptual model is that the intentional content of emotions is evaluative. ${ }^{26}$ Yet, how does aesthetic admiration, for example, make its subject aware of (apparent) evaluative properties, such as an object's determinate beauty?

On one prominent version of the perceptual model, typical emotional experiences do so through their valenced phenomenology, more specifically through an intentional feeling of favouring or disfavouring, which serves as an uptake of (as presenting) the relevant evaluative properties of the emotions' object. In this sense, emotional intentionality is affective intentionality. This felt favour or disfavour is described as a felt attitude towards the object, which discloses the relevant value. So, an emotion of aesthetic admiration about a painting includes a felt valenced attitude (felt favour) towards it, which is experienced as picking up

\footnotetext{
${ }^{24}$ Another option would be Julien Deonna and Fabrice Teroni's (2012: 76-89) view of emotions as felt bodily attitudes of action readiness.

25 Poellner 2016: 1. There are perceptualist views which don't think of emotions as involving disclosures of value. For example, neo-Jamesian perceptualist accounts, where the perception is of bodily states (see Prinz 2004; Barlassina and Newen 2014: 637-78). My interest is in accounts according to which emotions are perceptual experiences of value.

${ }^{26}$ See Poellner 2016: 8-11. See also Döring 2007: 363-94; Johnston 2001: 181-214 (cf. Deonna and Teroni 2012: 70; Dokic and Lemaire 2015: 235).
} 
on - as registering and so presenting - the determinate beauty of the painting. On this characterization, the valenced intentional attitude is experienced, according to Peter Poellner, as 'intelligibly motivated by [evaluative] features of the object itself' ${ }^{27}$

More could be said about this version of the perceptual model, yet it suffices for my purposes. Can it be productively applied to meta-emotions? Note, many of the features highlighted in sections 1 and 2 are congenial to it, such as meta-emotional experiences being intentional, having a felt phenomenology, and being motivated by their intentional object(s).

The first distinctive claim of the perceptualist model applied to meta-emotions is that metaemotions are felt disclosures - affective perceptual experiences - of the relevant evaluative properties of their target emotions, where those evaluative properties are the relevant thick evaluative properties, such as the disgusting, embarrassing, amusing, offensive, fearsome, etc. The idea that meta-emotions involve evaluative appraisals of their target emotion is common in the psychological literature, and the perceptualist model provides a distinctive take on this. ${ }^{28}$ Meta-emotions are claimed to be experienced as an uptake of - as presenting and so disclosing - evaluative properties of their target emotions. Consider the following explanation: I respond with embarrassment to your anger at $\mathrm{X}$, and in doing so my embarrassment discloses the target emotion as embarrassing (or, put otherwise, presents it under the aspect of the embarrassing). And whereas in the non-meta case the 'formal' object (i.e. the presented value property) can qualify any 'particular' object (i.e. a physical particular, person, event, or state of affairs), in the meta-emotion case the 'formal' object, the presented value property necessarily qualifies one specific type of 'particular' object, namely emotions themselves.

Yet, as in the non-meta case, we can ask how does a meta-emotional experience make its subject aware of the relevant evaluative properties (e.g. the embarrassing character of your anger; the repulsive character of my lust)? By applying the version of the perceptual model under consideration, we get the following: meta-emotions present evaluative properties of their target emotions through their affective intentionality - through a felt intentional attitude of favour or disfavour towards the target emotion - which registers, and so presents, those evaluative properties. Turning to a specific case, we get the following explanation. I respond with embarrassment to your anger at X, and in so doing my embarrassment registers that the target emotion (anger at $\mathrm{X}$ ) is embarrassing, through a felt valenced intentional attitude of

\footnotetext{
${ }^{27}$ Poellner 2016: 6. This claim only applies to emotions which are experienced as intelligibly motivated by evaluative features of their objects - so not recalcitrant emotions or reflex 'truncated' emotional responses.

${ }^{28}$ See Bartsch et al. 2010: 167-190; Jäger and Bänninger-Huber 2015: 795-805; Koven 2011: 1255 61; Mitmansgruber et al. 2009: 448-53).
} 
disfavour towards it. Taking another example, think of contempt for another's sadness about $\mathrm{X}$. In affectively responding with contempt to your sadness, my contempt discloses your sadness as contemptible, through a felt valenced intentional attitude of disfavour towards it which registers, and so presents, the evaluative property of the contemptible.

Importantly, as noted in section 1, we need a way of distinguishing between metaemotional experiences and other occurrent intentional states which take emotions as their targets. Now that we have the perceptual model on the table we can meet this constraint. Consider that I might believe that my partner's anger is embarrassing, or even see that my partner's anger is embarrassing, yet without experiencing any emotional response. On the perceptual model, at least part of the difference in the meta-emotional case - when I respond with embarrassment to my partner's anger - is that my meta-emotion presents that anger as embarrassing through its affective intentionality, that is through a felt intentional attitude of disfavour towards that anger, which discloses that evaluative property. In both the case of non-emotional belief and non-emotional perception there is not affective intentionality of this sort. $^{29}$

Stepping back from details of the view, is it plausible meta-emotional experience has evaluative content in this way? Consider the alternative, that the intentional content of metaemotional experience is non-evaluative, merely presenting non-evaluative properties of the target emotion. Possible candidates for the relevant non-evaluative properties could be facial profile, tone of voice, body language, verbal reports (as constitutive of the target emotion). However, the perceptualist would have to maintain that it is a misdescription of the phenomenology to say I typically experience a meta-emotional response to those nonevaluative physical features (and they are not present in reflexive cases; see section 4.1 for discussion). Further, even if those non-evaluative features of target emotions are present, I typically affectively respond to someone's aggressive posture as indicative of anger, or offensive tone as indicative of rudeness, and so those non-evaluative features of target emotions present as variously evaluatively qualified in meta-emotional experience. While more needs to be said to rule decisively in favour of the perceptualist claim here, if there is plausibility to the thought that meta-emotions involve evaluations of their target emotions, then the idea that meta-emotional experience typically has evaluative content is one plausible way of cashing this out.

Moreover, in light of the above, the perceptualist view suggests not only that metaemotional experiences have evaluative content, but their evaluative content is distinct from that of their target emotion. Take embarrassment at a friend's anger about X. On the

${ }^{29}$ I thank an anonymous referee for suggesting making this explicit. 
perceptualist view, my friend's anger about $\mathrm{X}$ represents $\mathrm{X}$ as offensive, and therefore has an evaluative content we can approximately characterize as ' $\mathrm{X}$ is offensive'. Yet, my metaemotion of embarrassment at my friend's anger does not present this anger itself as offensive but is presented as embarrassing through felt disfavour toward it.

However, a critic might object that it is incorrect to claim that meta-emotions have distinct evaluative content in this way. They might claim whatever evaluative content meta-emotions have, they inherit it, or 'catch it', from their target emotions. One might support this by pointing to an analogy with 'mirroring' emotions. Consider the following case. Say I am taking a flight, and there is unexpected heavy turbulence. I look to the flight attendant to gauge the situation and see they are petrified, which precipitates my becoming afraid. While my emotion (approximately) mirrors the evaluative content of the attendant's emotion - fear about the dangerous turbulence - this is not a meta-emotion of the kind under consideration. After all, I am not afraid of the attendant's emotion: my fear does not present the attendant's being petrified about the heavy turbulence as fearsome or dangerous; rather the turbulence is what is fearsome, not the target emotion. Such cases arguably involve emotional contagion, where becoming aware of someone else's emotional reaction to a particular object focuses my attention on the same object, and precipitates an emotion with approximately the same evaluative content. Put otherwise, I 'catch' the emotion, more specifically I 'catch' its content. $^{30}$

So, mirroring emotions about the same object is not the same as having an emotional response to another emotion, even if the means by which I come to share someone's emotion is through attention to their emotion. As such, these cases pose no barrier to the perceptualist claim that the evaluative content of meta-emotions is distinct from that of their target emotions.

In fact, consideration of such cases leads us to the following important claim. By claiming that the evaluative content of meta-emotions is distinct from that of their target emotion the perceptualist view taps into an important criterion for distinguishing meta-emotions from similar affective phenomena, such as emotional contagion or mirroring emotions, as considered above. To re-emphasize, one central aspect of those cases is that I 'catch' the evaluative content of their emotion. In the case considered above, that is the fearsomeness of the situation - I share in that fearsome appraisal, which as noted is categorically not what happens in meta-emotions. Furthermore, cases where the meta-emotional response and the target emotion are the same type - anger towards anger, or pity for pity - does not undermine this claim. The claim is about the token distinctness of the evaluative content of the metaemotion from that of the target emotion, and so the view need not deny that one's meta-

${ }^{30}$ See Gordon 1996: 11-21. See Goldie 2000: 189-194. 
emotional response can be of the same type as the target emotion without inheriting its evaluative content from that target emotion.

Finally, consider meta-emotions as contrasted with empathetic responses, where there is some conscious attempt to share in the emotion of another subject, rather than a "passive catching' as in emotional contagion cases. As Goldie defines empathy, it is a 'process by which a person centrally imagines the narrative (the thoughts, feelings, and emotions) of another person' ${ }^{31}$ Consider the following example. A doctor, having met with a grief-stricken patient whose care they have been in charge of for some time, is writing up a psychological report. In doing so they seek to convey the character of the grief and imagine the narrative of their patient's emotion. Part of imaginatively inhabiting the perspective of the patient is imagining how the world seems to them in grief, and so the evaluative content of their grief (the loss of a loved one as grievous). In that sense, the relevant imaginative experience aims to take up the content, the 'thoughts, feelings and emotions' of the patient's experience, of what is another person. Whereas, according to the perceptual model, the evaluative content of the meta-emotional experience is not that of a different subject's experience, but precisely the subject undergoing the meta-emotional experience.

\subsection{Normative status}

Building on this discussion we can note a distinctive feature of meta-emotions that the perceptual model has a substantive take on. Julien Deonna and Fabrice Teroni note, 'your disappointment regarding the anger you felt at being confronted with your wrongdoing might be the beginning of an assessment of your anger as inappropriate...' ${ }^{32}$ Generalizing, the thought is that the meta-emotional response taps into something important about what I will call the 'normative status' of the target emotion. Let me explain this term in more detail and contrast it with, and relate it to, what has been said previously about the evaluative properties which meta-emotional experiences present their target emotions as having.

In addition to the relevant evaluative properties, the disgusting, embarrassing, amusing, fearsome, offensive (etc.) there are also a range of normative properties, such as the justified, unjustified, warranted, unwarranted, appropriate, inappropriate. Let's focus on the notion of appropriateness. We need to be careful, however, because in the affective domain talk of appropriateness can mean different things. For example, anger towards a particular individual's behaviour might be prudentially inappropriate if the individual is our boss and is likely to look poorly on such an emotional display. Alternatively, we might think it morally

\footnotetext{
${ }^{31}$ Goldie 2000: 195.

${ }^{32}$ Deonna and Teroni 2012: 18.
} 
inappropriate to feel a sense of admiration or awe for serial killers. ${ }^{33}$ However, the sense of appropriateness we can focus on in the present context is epistemic appropriateness, in terms of correctly representing the object as it evaluatively is.

Applied to meta-emotions, the normative status of the target emotion - the anger I am embarrassed by - is a matter of whether the target emotion itself (the anger) is epistemically appropriate to its particular object (say the late waiter which is object of the anger), in terms of evaluative properties that particular object does or does not possess (i.e. whether the waiter's behaviour really is offensive or not, and so is, or is not, as the target emotion of anger presents it as being).

The perceptualist model provides a distinctive take on these issues. Arguably some metaemotional experiences are not 'silent' with respect to the normative status of their target emotions. Rather, in addition to presenting the relevant evaluative properties of the target emotion itself, they also present the normative status of their target emotion.

The way meta-emotions putatively do this can be described as follows: for some metaemotions, their felt valenced attitudinal component (felt favour or disfavour) is experienced as intelligibly motivated by the normative status of the target emotion. For example, in anger, I might experience felt disfavour as the appropriate (so intelligible) response to your jealousy about X. As such, it makes senses to be angrily responding as I am, insofar it seems to me that what partly constitutes that jealously being offensive is that jealousy about $\mathrm{X}$ itself is an inappropriate response to X. The meta-emotion would, therefore, have an intentional content approximating to 'inappropriate jealousy which is therefore offensive'. Alternatively, I might experience felt favour to be the appropriate (so intelligible) response to my indignation about $\mathrm{X}$, such that it makes sense to be admirably responding as I am, insofar as it seems to me that what partly constitutes indignation being admirable is that it is the appropriate response to X. The meta-emotion would, therefore, have an intentional content approximating to 'appropriate indignation which is therefore admirable'.

Note, on this picture, the normative status of target emotions is something that can be part of a way the object of a meta-emotional experience seems in a non-doxastic phenomenal sense. More generally, if normative properties can be non-doxastically directly presented in experience then, given our context, we might extend this to claims about meta-emotional experience. The contents of meta-emotions sensitive to the normative status of their target emotion would, of course, be more complex than otherwise, and perhaps a story might have to be told about such 'high-level' contents as including normative properties 'cognitively penetrating' non-doxastic experiences. Nonetheless, the perceptual model provides us with an interesting way of making sense of the claim that the normative status of the target emotions

\footnotetext{
${ }^{33}$ See Tappolet 2016: Ch.3 for an overview of these different senses of appropriateness.
} 
of meta-emotions can be part of what is experientially presented (although more need to be said on these issues).

In further clarification of this picture, let me note two things. First, even if we accept that meta-emotions present the normative status of their target emotions, they need only do so sometimes. It is not plausible that meta-emotional responses always include this dimension, and the perceptualist model need not commit to this claim. Let me say more about the contrast here by way of an example. Say a teenager is out for a meal with their parents, and their father begins to remonstrate with the waiter, displaying anger. The teenager is overcome with embarrassment about their parent's emotion, and (on the perceptual model) it is experientially presented under the aspect of the embarrassing. It seems entirely possible that the teenager can undergo this meta-emotional experience without their experience having anything to say, so to speak, about the normative status of the target emotion itself. There might just be something about their parent displaying anger which they find embarrassing regardless, as it were. Alternatively, consider someone who experiences annoyance whenever they see that their colleagues are in a good mood. Again, there need be no experience of the normative status of the target emotion. Note, this reflects a phenomenological difference between cases. The precise explanation of why a meta-emotional experience may or may not have anything to say on the normative status of the target emotion will likely be highly dependent on the individual's affective psychology and context-specific features of the situation.

Second, a critic might argue that while it is phenomenologically acceptable to say that subjects can be aware of target emotions as (in)appropriate in a given situation, nonetheless there is no requirement that I experience the normative status of the target emotion's object. Consider the following example. If in embarrassment I experience my friend's anger at the waiter as inappropriate, this may also involve a non-experiential fact-awareness that, for example, it wasn't the waiter's fault that the food arrived late, or that this isn't something worth getting angry about (the relevant evaluative property of 'offensiveness' or 'blameworthiness' not being instantiated). Yet, the waiter's being faultless - the normative status of the target emotion's object - doesn't itself need to be experientially presented ('disclosed') by my meta-emotion, but can be part of its putative cognitive base, in this case a belief on my part with a content that reflects the normative states of the target emotion's object. ${ }^{34}$ The perceptual model can concede that this is how the normative status of the target emotion's object is sometimes represented in meta-emotional experience, namely in a doxastic way.

\footnotetext{
${ }^{34}$ I thank an anonymous referee for suggesting this objection.
} 


\section{Objections and Challenges}

\subsection{Reflexive and non-reflexive meta-emotions}

I now consider some further objections and challenges to the perceptual model applied to meta-emotions. First, let's remind ourselves of the basic vs non-basic distinction from section 2. There it was said that basic cases are those in which the target emotion is directly presented, non-basic cases being those in which the target emotion is merely represented indirectly. ${ }^{35}$

However, we might think there are two problems with this distinction for the perceptualist model. First, consider that the requirement of a direct presentation of the target emotion in basic cases of meta-emotional experience seems most applicable to contexts where we have two emotional subjects. For example, the subject of the target emotion (s1), where that target emotion is perceptually present to the subject of the meta-emotional response (s2). Yet, how do we have perceptual access to someone else's emotion in this way? Might there necessarily be a mediating thought to ground an inference from observed emotional behaviour to attribution of emotion, on the basis of which s1's emotion can become the target emotion of s2's meta-emotion? Such a mediating thought could involve analogical reasoning regarding the link between emotional behaviour and experience in my own case, which grounds that inference. Given this worry, basic case non-reflexive meta-emotions generate a version of the other minds problem, an inference-by-analogy answer to which threatens the analysis from section 2, insofar as these cases would necessarily involve indirect representations (i.e. thoughts or judgements), and so would ex hypothesi always be non-basic cases.

Second, while this problem does not arise for reflexive meta-emotions - an inference from observed emotional behaviour to ascription is not required in my own case - in what sense is that target emotion directly present? The worry is that it is difficult to make sense of our own emotions being directly perceptually present, and so meta-emotions which target them would necessarily be non-basic cases. ${ }^{36}$

There are responses to these problems within the perceptualist framework. Taking the meta-emotion other minds problem first consider the following. It seems phenomenologically correct to say that we often experience emotionally expressive behaviour, including distinctive facial features and changes, as constituting the presence of emotions - at least when we have no reason to doubt emotional sincerity. Put otherwise, we seem to have access to other people's emotions; in favourable circumstances, we seem to 'see' the emotions of other people. ${ }^{37}$ As Joel Smith frames this 'perceptuality' claim, 'suitably placed and endowed

\footnotetext{
${ }^{35}$ See Poellner 2016: 1-3 for discussion of derivative (i.e. indirect) cases within the perceptual model of emotion.

${ }^{36}$ This taps into 'Howards Challenge' - see the end of the subsection.

${ }^{37}$ See Goldie 2000: 182 .
} 
observes can perceive other's emotions' ${ }^{38}$ In a typical statement of it, Quassim Cassam says 'what displays or manifestations of the anger do is to reveal his state of mind without being his state of mind; one perceived his anger by perceiving displays of it ${ }^{,}{ }^{39}$ The motivations for the perceptuality claim are varied, but amongst them are the fact that we paradigmatically speak in this way; we say that we see the sadness in someone's crying, or someone's anger in their frown. Further to this, perception in such contexts may be read factively, and, as such, perception of others emotions would provide non-inferential knowledge of their emotions.

Let me now say more about this picture. One point which bears emphasizing is that the relevant perception of emotion seems in an important respect different from the perception of the relevant emotional expression. We seem to have an instance of perceiving one thing in virtue of perceiving something else, as a kind of dependent perception. Building this into the perceptuality claim, we perceive the other's anger in virtue of perceiving their frown. Generalizing, we perceive the emotion as the emotion it is in virtue of perceiving the relevant expressive behaviour, which in some sense constitutes it.

There is then a further question on how to cash out this form of dependent perception of emotion. Here is one proposal: we perceive the emotion of another subject as the emotion it is by perceiving something which is plausibly, and in part, constitutive of it, namely its expressive behaviour. ${ }^{40}$ Here is how one defender of the perceptual model articulates this claim:

[T] he other's mental state in such cases is not, or not always, a 'distinct existence' from his directly given expressive behaviour, and merely contingently linked with it. Otherwise, my perceptual experience of the other's behaviour would not give me direct perceptual access to that mental state. The claim has to be that the other's expressive behaviour is at least sometimes part of his relevant mental state, such that that mental state is itself, in the right circumstances, perceptually given to me in my perceptual access to the other's expressive behaviour. (Poellner 2016: 24) (1 $^{4}$

Applied to non-reflexive meta-emotions, we now get the following claim: in favourable circumstances, non-reflexive meta-emotions involve non-inferential perceptual access to the

\footnotetext{
${ }^{38}$ Smith 2018: 130.

${ }^{39}$ Cassam 2007: 165; See also Green 2007: 89; Goldie 2000: 182

${ }^{40}$ Cf. Smith 2018: 130-48 who rejects this 'part-whole' proposal based on issues concerning the ontological status of emotions vs emotional expressions.

${ }^{41}$ See also Stein 1980: 87,89.
} 
relevant target emotion insofar as that target emotion is perceptually given to me in virtue of my perceptual experience of the relevant expressive behaviour, which is a constitutive part of that target emotion.

A full defence of this view about our access to others' emotions is beyond the scope of this paper, but let me note a related issue. Remember the claim of the perceptual model is not merely that one has a direct presentation of the relevant target emotion, but rather that one has a perceptual experience as of evaluative properties of the relevant target emotion (and in some cases the normative status). As such, the 'perceptuality' claim applied to meta-emotions would be as follows. Suitably placed and endowed observers can, on the basis of their metaemotional experiences, perceive evaluative properties of other's emotions' in virtue of having a perceptual experience of the relevant emotional expression. So, while basic case nonreflexive meta-emotions would have, as their relevant cognitive base, this form of perception of another emotion (making them not self-standing intentional relations to those target emotions), they may well still be self-standing intentional relations to the evaluative properties of those target emotions. According to the perceptual model, the distinctive contribution of the meta-emotion, therefore, is the affective presentation of the target emotion as having the relevant evaluative properties. While not deprived of intuitive plausibility more needs to be said on this issue. ${ }^{42}$ However, what has been said is enough to meet the worry that in basic non-reflexive cases the meta-emotional subject also needs to have an indirect representation to the effect of entertaining a mediating thought about emotionally expressive behaviour (one with the content 'in my case, so the same in this case) - which grounds some purported inference to ascription. This is not the case, given what has been said about the perceptuality claim, so such cases can still be classified as basic cases on the perceptual model.

Moving on, what about the problem of perceptual presence for reflexive meta-emotions? What the perceptualist should say is that the target emotion - in this case, my own - is directly experienced insofar as its occurrent instantiation, as experientially present, motivates the meta-emotional response. Expanding on this, I experience an emotion, and then, as part of a temporally extended emotional event, experience that emotion as motivating a metaemotional response, which has as its target the first emotion (e.g. my anger about X motivating embarrassment about that anger). So, in such cases, the prior experiential presence of the

\footnotetext{
${ }^{42}$ See Poellner 2016: 24-6 on this. I thank an anonymous referee for pushing me to say more about this.
} 
target emotion plays the same role in underwriting intentional causality that the perceptual presence of the target emotion plays in non-reflexive cases. ${ }^{43}$

The above analysis also addresses the related objection that I do not (and perhaps cannot) synchronously experience two affective states - my own emotion, say anger, and at the same time a meta-emotional response of embarrassment about that anger. This seems typically correct, but given the above, reflexive meta-emotions on the perceptualist model need not contravene this. Moreover, in basic reflexive cases, there is no need to suppose any introspective act takes place. In line with the analysis in section 2, the meta-emotional response is a first-order intentional experience directed toward the relevant target emotion.

Keeping the above analysis in mind the perceptual model now also has the resources to meet the objection that while the idea of affectively perceiving another emotion seems applicable in non-reflexive cases, we do not 'perceive' anything in reflexive cases. Remember that an 'affective-perceptual experience of value' when applied to meta-emotions is understood as referring to a felt disclosure of value. So, as long as the target emotion was experientially present in the reflexive case (in the sense defined above), then the perceptualist will argue that it is available to be taken up by a meta-emotional response. As such, the perceptual model of meta-emotions, so understood, can arguably deal with both non-reflexive and reflexive cases as types of basic cases, as long as 'affective-perceptual experience of value' is not read, with respect to the reflexive case, as having to literally involve a senseperceptual experience of the target emotion as instantiated in the subject's external environment.

Finally, what has been said allows us to meet 'Howards Challenge'. Remember the challenge is for any theory of emotions, applied to meta-emotion, to explain basic case reflexive meta-emotions in such a way as to respect the fact that they can be self-standing intentional relations to the emotions which they are about (not requiring separate cognitive bases). Given the framework for thinking about basic case reflexive meta-emotions above, the perceptualist model can respect this. The basic case reflexive meta-emotion need not involve a sense-perceptual experience of the target emotion as a 'cognitive base' state (much less a judgement that it has obtained). Rather, to re-emphasize, what plays the role that senseperception plays in the non-reflexive basic cases, is the way I experience the relevant target emotion, which is my own, and then, as part of a temporally extended emotional event, experience that occurrent emotion as motivating a meta-emotional response. The target emotion is in this sense directly presented on the basis of prior experiential presence.

\footnotetext{
${ }^{43}$ This is not to claim we cannot be mistaken about the target emotion in reflexive cases. There is no commitment to the idea that we have incorrigible knowledge of our emotions.
} 


\section{4.ii Epistemic issues}

Epistemological challenges can be raised against the perceptualist model of meta-emotions as expressed by the following questions. (1) Do meta-emotional experiences have standards of correctness in the same way as typical intentional states, and (2) what (if any) evaluative judgements might a meta-emotional experience give one reason for. One of the standard motivations for the perceptual model of the emotions is a putative epistemic analogy between emotional and paradigmatic sense-perceptual experience. It is claimed emotions can play the same (or similar) rationalizing role as sense-perceptual experience by constituting reasons, and so defeasible justification, for corresponding evaluative beliefs. ${ }^{44}$ Do similar ideas carry over for meta-emotional experience?

Taking (1) first, we might frame a standard of correctness for meta-emotions on the perceptual model as follows:

Standard of correctness for meta-emotions: a meta-emotion is justified iff the target emotion really has the evaluative property it is represented as having.

To see how the above standard of correctness could be met take the following example: embarrassment at my anger towards $\mathrm{X}$ - which is experienced as disclosing the target emotion as embarrassing - is correct iff anger towards $\mathrm{X}$ really is embarrassing. However, what (if anything) determines whether 'anger towards $\mathrm{X}$ ' is, in fact, embarrassing? We might answer that a whole range of considerations could go into determining whether a particular emotional display of anger is, in fact, embarrassing, such as social context and norms. Although one important consideration is the normative status of the target emotion. Remember, target emotions have a normative status, specified in terms of the relation of epistemic appropriateness between the target emotion and its objects evaluative properties, i.e. whether the target emotion itself is epistemically appropriate to the way its object is. This is plausibly something that we can investigate ("was $\mathrm{X}$ really offensive and so worthy of the angry response?'), and this seems an important consideration, alongside others, in determining whether the target emotion itself possesses the relevant evaluative property represented by the meta-emotional response. This is reflected in the common-sense thought that we think it more justified to respond with embarrassment to anger if the anger itself was inappropriate in the circumstances.

However, the perceptual model claimed that in certain cases meta-emotions themselves can be sensitive to this normative status. In those cases, there would be the possibility of a

\footnotetext{
${ }^{44}$ On Epistemic Perceptualism see Tappolet 2012: 205-22; Döring 2007: 363-94; Cowan 2016: 59-81, (cf. Brady 2013: Ch.3).
} 
meta-emotion veridically presenting the normative status of its target emotion, insofar as it picked up on that relation of appropriateness between that target emotion and evaluative properties of its object. However, note how complex the standard of correctness ends up being. What is required for veridicality on this score is an accurate meta-emotional representation of (a) the target emotion's object evaluative properties (b) the target emotion's evaluative take on its object, and so its evaluative content, and (c) the relation between (a) and (b), which arguably constitutes the target emotions normative status (whether it was appropriate to its object qua possessing the relevant evaluative property). Getting this right is a complex requirement for justification since there is a variety of possible misrepresentation.

Further, can all this representational work be cashed out in terms of the affective intentionality of meta-emotions, as purported affective disclosures of the normative properties of their target emotions? The perceptual model is committed to saying that such a thing is not only possible but central to capturing the 'assessorial' character of a proportion of metaemotional experience (see 3.2). The perceptualist might suggest that being able to articulate how one could have justified meta-emotions which are sensitive to the normative status of their target emotions is a promising feature of their model. So, while there is the possibility of various misrepresentations, there is also the possibility of satisfying the conditions. And while more would be required to defend this aspect of the view in full, the perceptualist has resources to draw on.

The perceptual model also has a response to question (2) above, which asks what evaluative judgements might a meta-emotional experience give one reason for. The natural response would be that meta-emotional experience gives one a prima facie (provisional) reason to judge that the target emotion has the evaluative properties it is represented as having (e.g., insofar as I experience embarrassment toward your anger at X, then that gives me a prima facie reason to judge that anger at $\mathrm{X}$ is embarrassing).

More interestingly, however, in those cases where there is a purported experiential disclosure of normative status, those meta-emotional experiences would give one a prima facie reason to judge that the target emotion has the normative status it is presented as having - as epistemically appropriate (or not) to its object. If the latter view is defensible, some metaemotions would have a distinctive role to play in being experiential guides in reflective assessments of the normative status of the relevant target emotion. I now say more about this feature and how the perceptualist model explains it.

Taking a step back, consider that much of our reflective assessment of our and others' emotions consists in normative judgements about the epistemic appropriateness (or not) of the relevant target emotion. This is expressed in claims to the effect that particular instances or fear, embarrassment, pride, etc., were (in)appropriate, in the sense of (not) matching the 'way things evaluatively are'. Yet, if meta-emotions can be the 'beginning' of an assessment 
concerning the normative status of our and others' emotions, then they pre-reflectively tap into that normative status, that is prior to reflective assessment.

Let me flesh this out with an example to clarify the distinction between reflective assessment and pre-reflective meta-emotional assessment. Take again the example of being embarrassed at the anger of my friend towards the waiter concerning the long delay in the arrival of the entrée. Arguably, and as was outlined in section 3.2, that anger can prereflectively seem inappropriate - it can seem not to fit the situation as my meta-emotional experience presents it. We might, therefore, talk of meta-emotions as seeming to disclose the normative status of the target emotion as an 'assessorial hunch'.

Contrastingly later that evening, after my friend has calmed down, I reflect on what happened. I consider whether it might have been the case that the lateness was the waiter's fault, that it was offensive in a certain respect, and that therefore the anger of my friend may have been epistemically appropriate. Say my friend informs me that he saw the waiter go out for a cigarette just as our food was put up to the pass and that when he came back he was more concerned to converse with his colleges than bring the food. Made aware of this, I might draw a different conclusion to the 'assessorial hunch' of my meta-emotional experience. I might judge that anger was, in fact, appropriate, and that my meta-emotion of embarrassment, which seemed to disclose otherwise, was not sufficiently sensitive to a range of evaluatively-relevant considerations. The perceptual model of meta-emotions explains this contrast between a reflective assessment of emotions normative status and a meta-emotional 'assessment' by providing a way of theorizing the relevant class of experiences and their assessorial dimension. ${ }^{45}$

A further interesting point on these issues is that insofar as we can draw the above distinction then the normative status which is seemingly pre-reflectively disclosed in some meta-emotional experience could figure as what we might call an 'experiential guide' in those further reflections. Put in more philosophical terms, the 'assessorial hunch' of the metaemotional response would be a defeasible reason for making a normative judgement about the epistemic appropriateness (or not) of the relevant target emotion. ${ }^{46}$ Say, amending the example above, no such evaluatively-relevant considerations come to light that might justify finding the waiter's lateness offensive. In such a case, I might come to the reflective assessment that things were normatively as my meta-emotional experience presented them as

\footnotetext{
${ }^{45}$ For further discussion of the role meta-emotions play in explaining the criteria by which we regulate our emotional responses see Howard 2015: 3; Mendonça 2013: 390-396; Jäger and Bänninger-Huber 2015: 805-808.

${ }^{46}$ For a discussion of the epistemic advantage for meta-emotions over non-emotional evaluative judgements about emotions see Howard 2015: 11, 17.
} 
being. As such, we should take these purposed experiential disclosures of the normative status of the relevant target emotion seriously, as a consideration to be weighed in a reflective assessment. Meta-emotional responses would, therefore, have a significant role to play in an 'all things considered' assessment.

\section{Conclusion}

In this paper, I have clarified the central features of meta-emotions and surveyed the prospects of the perceptual model as applied to them. It has been argued that the perceptual model provides us with a theoretical framework within which to articulate what is distinctive about meta-emotions and their role in our emotional lives. Yet, while the perceptual model provides a distinctive way of theorizing these states, it faces challenges. The view has resources to draw on, yet more needs to be said for a full defence. Let me summarise the key challenges that are still faced: (1) articulating in more detail the claim that the normative status of target emotions can be experientially disclosed in meta-emotional experience, without thoughts or judgments; (2) a fully developed meta-emotional epistemology which expands on the reflections provided in 4.2 , further detailing the distinctive epistemic roles of meta-emotions regarding how we assess affective states; and (3) the broader role of meta-emotional experiences in the affective domain, including their connection to the development of metaemotional dispositions and recalcitrant meta-emotions. As a final point, those who are sceptical about the perceptual model, and its extension to meta-emotions, should explain how their preferred theory can capture the distinctive features of meta-emotions as outlined here.

\section{References}

Barlassina, L and Newen A. (2014) 'The Role of Bodily Perception in Emotion: In Defense of an Impure Somatic Theory' in Philosophy and Phenomenological Research 83 (3), 637-78.

Bartsch, A., Appel, M., and Storch, D. (2010). 'Predicting emotions and metaemotions at the movies' in Communication Research, 37 (2), 167-90.

Brady, M. (2007) 'Recalcitrant Emotions and Visual Illusions' in American Philosophical Quarterly 44 (3), 273-84.

- (2013) Emotional Insight: The Epistemic Role of Emotional Experience. Oxford: Oxford University Press.

Cassam, Q. (2007) The Possibility of Knowledge. Oxford: Oxford University Press.

Cowan, R. (2016) 'Epistemic Perceptualism and Neo-Sentimentalist Objections' in Canadian Journal of Philosophy 46 (1), 59-81.

Crane, T. (1998) 'Intentionality as the Mark of the Mental' in A. O'Hear (ed.), Contemporary Issues in the Philosophy of Mind. Cambridge: Cambridge University Press, 229-51.

Deonna, J. and Teroni, F. (2012) The Emotions: A Philosophical Introduction. London: Routledge.

Dokic, J. and Lemaire, S. (2015) ‘Are Emotions Evaluative Modes?’ in dialectica 69 (3), 271-92. 
Döring, S. (2007) 'Seeing What to Do: Affective Perception and Rational Motivation' in dialectica 61 (3), 363-94.

— (2014) 'Why Recalcitrant Emotions Are Not Irrational' in S. Roeser and C. Todd (eds) Emotion and Value, 124-36. Oxford: Oxford University Press.

Döring, S. and Lutz, A. (2015) 'Beyond Perceptualism: Introduction to the Special Issue' in dialectica 69 (3), 259-70.

Eisenberg, N. (1996). 'Metaemotion and socialization of emotion in the family - A topic whose time has come: Comment on Gottman et al. (1996)' in Journal of Family Psychology 10 (3), 269-76.

Ekman, P. (1999) 'Basic Emotions' in T. Dalgleish and T. Power (eds) The handbook of cognition and emotion, 45-60. Chichester: John Wiley.

Frijda, N. (1987) The Emotions. Cambridge: Cambridge University Press.

Goldie, P. (2000) The Emotions: A Philosophical Exploration. Oxford: Oxford University Press.

Gordon, R. (1996) 'Radical Simulation', in Carruthers, C. and Smith, P. K. (eds) Theories of Theories of Mind. Cambridge: Cambridge University Press, 11-21.

Green, M. (2007). Self-Expression. Oxford: Oxford University Press.

Helm, B. W. (2001) 'Emotions and Practical Reason: Rethinking Evaluation and Motivation' in Noûs $35(2), 190-213$.

Howard, S. A. (2015) 'Metaemotional Intentionality' in Pacific Philosophical Quarterly 97 (2), 1-23.

Jäger, C., and Bartsch, A. (2006) 'Meta-emotions' in Grazer Philosophische Studien 73 (1), 179-204.

Jäger, C. and Bänninger-Huber, E. (2015) 'Looking into meta-emotions' in Synthese 192 (1), 787-811. James, W. (1884) 'What is an Emotion' in Mind 9(34), 188-205.

Johnston, M. (2001) 'The Authority of Affect' in Philosophy and Phenomenological Research 63 (1), $181-214$.

Kenny, A. (1963) Action, Emotion and Will. London: Routledge.

Koven, N. S. (2011) 'Specificity of metaemotion effects on moral decision making' in Emotion 11 (5), 1255-61.

Lambie, J. (2009) 'Emotion Experience, Rational Action, and Self-Knowledge', in Emotion Review 1 (3): $272-80$.

Marcel, A. J., and Lambie, J. A. (2002) 'Consciousness and the Varieties of Emotion Experience: A Theoretical Framework', in Psychological Review 109 (2), 219-59.

Mendonça, D. (2013) 'Emotions about Emotions’ in Emotion Review 5 (4), 390-6.

Mitmansgruber, H., Beck, T. N., Höfer, S., \& Schüßler, G. (2009). 'When you don't like what you feel: Experiential avoidance, mindfulness and metaemotion in emotion regulation' in Personality and Individual Differences 46 (4), 448-53.

Norman, E. and Furner, B. (2016) "The Concept of "Metaemotion": What is There to Learn From Research on Metacognition?' in Emotion Review 8 (2), 187-93.

Nussbaum, C. N. (2001) Upheavals of Thought: The Intelligence of Emotions. Cambridge: Cambridge University Press.

Poellner, P. (2016) 'Phenomenology and the Perceptual Model of Emotion' in Proceedings of the Aristotelian Society, Vol. CXVI, Part 3. 
Searle, J. (1983) Intentionality: An Essay in the Philosophy of Mind. New York: Cambridge University Press.

Solomon, R. (1976) The Passions. Doubleday.

Smith, J (2018) 'The Perceptibility of Emotion' in Narr, H and Teroni, F. (eds.) The Ontology of Emotions. Cambridge: Cambridge University Press, 130-48.

Stein, E. (1980) On the Problem of Empathy. Washington DC: ICS Publications.

Stocker, M. (2010) 'Intellectual and Other Nonstandard Emotions' in P. Goldie (ed) The Oxford Handbook of Philosophy of Emotion, 401-23. Oxford: Oxford University Press.

Tappolet, C. (2012) 'Emotions, Perceptions, and Emotional Illusions' in Calabi, C. (ed) Perceptual Illusion: Philosophical and Psychological Essays. New York: Palgrave-Macmillan, 205-22.

Teroni, F. (2007) 'Emotions and Formal Objects' in dialectica 61 (3), 395-415.

Zagzebski, L. (2003) 'Emotion and Moral Judgement' in Philosophy and the Phenomenological Research 66 (1): 104-124. 